2001 98: 368-373

doi:10.1182/blood.V98.2.368

\title{
Increased thrombogenesis and embolus formation in mice lacking glycoprotein V
}

Heyu Ni, Vanitha Ramakrishnan, Zaverio M. Ruggeri, Jessie M. Papalia, David R. Phillips and Denisa D. Wagner

Updated information and services can be found at:

http://bloodjournal.hematologylibrary.org/cgi/content/full/98/2/368

Articles on similar topics may be found in the following Blood collections:

Hemostasis, Thrombosis, and Vascular Biology (2496 articles)

Information about reproducing this article in parts or in its entirety may be found online at:

http://bloodjournal.hematologylibrary.org/misc/rights.dtl\#repub_requests

Information about ordering reprints may be found online at:

http://bloodjournal.hematologylibrary.org/misc/rights.dtl\#reprints

Information about subscriptions and ASH membership may be found online at:

http://bloodjournal.hematologylibrary.org/subscriptions/index.dtl

Blood (print ISSN 0006-4971, online ISSN 1528-0020), is published semimonthly by the American Society of Hematology, 1900 M St, NW, Suite 200, Washington DC 20036.

Copyright 2007 by The American Society of Hematology; all rights reserved.

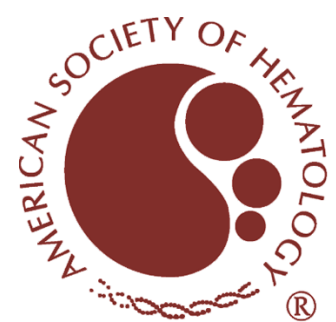




\section{Increased thrombogenesis and embolus formation in mice lacking glycoprotein $\mathrm{V}$}

Heyu Ni, Vanitha Ramakrishnan, Zaverio M. Ruggeri, Jessie M. Papalia, David R. Phillips, and Denisa D. Wagner

The glycoprotein (GP) Ib-V-IX complex plays a critical role in initiating platelet adhesion to von Willebrand factor (vWF) at the site of vascular injury. The complex also forms a high-affinity binding site for thrombin. Using an intravital microscopy mouse model, it was previously established that vWF plays a critical role in mediating platelet adhesion and thrombus formation following mesenteric arteriolar injury induced by ferric chloride. Further characterization of this model showed that these thrombotic events were also thrombin dependent. Using this vWF- and thrombin-dependent model, this study shows that GP $V$ gene deficiency significantly accelerates both platelet adhesion and thrombus formation in mice following arteriolar injury. The time required for vessel occlusion in GP V-deficient (GP $\mathrm{V}^{-/-}$) mice was significantly shorter than that in wild-type mice. Interestingly, large emboli were also produced in $\mathrm{GP} \mathrm{V}^{-/-}$mice, but not in wild-type mice, causing frequent downstream occlusion. However, when the 2 genotypes were compared in the in vitro perfusion chamber where thrombin was inhibited by hep- arin, no significant differences were found in either initial single-platelet adhesion or thrombus volume. These results demonstrate that GP V ${ }^{-1-}$ mice have accelerated thrombus growth in response to vascular injury and suggest that this is caused by enhanced thrombin-induced platelet activation rather than enhanced binding of GPIb-V-IX to vWF. Absence of GP V also compromises thrombus stability. (Blood. 2001;98:368-373)

๑) 2001 by The American Society of Hematology

\section{Introduction}

The platelet membrane glycoprotein (GP) Ib-IX-V complex, together with its ligand, von Willebrand factor (vWF), is involved in initiating platelet adhesion at high shear. ${ }^{1,2}$ The importance of GP Ib-IX-V to platelet biology has been underscored by studies of Bernard-Soulier syndrome, an inherited bleeding diathesis caused by an absence of this complex. ${ }^{3}$ The complex consists of 4 transmembrane subunits: GP Ib $\alpha, \mathrm{Ib} \beta$, IX and $\mathrm{V}$, in the ratio $2: 2: 2: 1 .^{4,5}$ The $\mathrm{vWF}$ binding function has been attributed to the GP $\mathrm{Ib}$ subunit, and the functional domains on GP Ib and vWF that interact have been identified. ${ }^{6,7}$ Stable platelet adhesion and aggregation are mediated in addition by several integrin receptors and their ligands, such as $\alpha 2 \beta 1$ with collagen and $\alpha \operatorname{IIb} \beta 3$ with fibrinogen and vWF. ${ }^{1,2}$ The GP Ib-V-IX complex is also involved in platelet aggregation. ${ }^{8,9}$ Finally, fibrinogen and fibrin converted from fibrinogen by thrombin appear important for thrombus stabilization at the site of vascular injury. ${ }^{10,11}$

In addition to these roles in platelet adhesion and aggregation through the binding of vWF, the GP Ib-IX-V complex has also been shown to interact with thrombin. One interaction is with GPIb, an activity first established by the demonstration that glycocalycin, a hydrolytic fragment of GP Ib $\alpha$, bound thrombin. ${ }^{12}$ This binding has been implicated in thrombin-induced platelet stimulation because platelets from patients with Bernard-Soulier syndrome also show an impaired response to thrombin. ${ }^{13}$ In addition, antibodies that block thrombin binding to GP Ib $\alpha$ also partially inhibit thrombininduced platelet responses. ${ }^{13} \mathrm{~A}$ second interaction of thrombin with GP Ib-IX-V is the thrombin-catalyzed hydrolysis of GP V, an event that occurs during thrombin-induced platelet stimulation. ${ }^{14}$ Recent

From the Center for Blood Research and Department of Pathology, Harvard Medical School, Boston, MA; COR Therapeutics, South San Francisco, CA; and the Scripps Research Institute, La Jolla, CA.

Submitted July 25, 2000; accepted March 24, 2001.

Supported in part by National Institutes of Health grants P01 HL 56949 and R37 HL41002 (to D.D.W.), HL 31950 and HL 42846 (to Z.M.R.). H.N. is a fellow of the Heart and Stroke Foundation of Canada. studies have evaluated the functional significance of GP V hydrolysis by gene targeting. In one study, Ramakrishnan and coworkers found that $\mathrm{GP} \mathrm{V}^{-1-}$ platelets aggregated at lower concentrations of thrombin than wild-type platelets, suggesting that GP V negatively modulates thrombin-induced platelet responses. ${ }^{15}$ Subsequent studies by these authors showed that proteolytically inactive forms of thrombin induce robust stimulatory responses in GP V null mouse platelets, suggesting that the thrombin receptor function of GP Ib is unmasked by proteolysis of GP V and consummated by thrombin acting as a ligand to the remaining GP Ib-IX complex. This signaling mechanism could also be generated by proteolytically inactive thrombin on normal platelets previously depleted of GP V by proteolytically active thrombin hydrolysis, suggesting this mechanism was involved in platelet biology. ${ }^{16}$ However, another study of the GP $\mathrm{V}^{-1-}$ mouse by Kahn and coworkers ${ }^{17}$ found, in contrast, that the thrombin responsiveness of platelets was not affected by $G P V$ gene targeting. Although the basis for this discrepancy is not known, differences in the methods used for blood collection may have been involved. ${ }^{16}$

The present study was initiated to address 2 questions concerning GP Ib-IX-V. First, to clarify the phenotype of the GP $\mathrm{V}^{-1-}$ mouse, we elected to determine whether GP V deficiency affected thrombosis in a thrombin-dependent in vivo model, and second, to determine whether the absence of GP V affected the adhesion function of GP Ib. Neither GP Ib-transfected Chinese hamster ovary $(\mathrm{CHO})$ cells lacking GP $\mathrm{V}^{18}$ nor platelets from GP V-deficient mice ${ }^{17}$ show defects in $\mathrm{vWF}$ binding in a perfusion chamber. Static platelet adhesion assays to immobilized vWF similarly

Reprints: Denisa D. Wagner, The Center for Blood Research, 800 Huntington Ave, Boston, MA 02115; e-mail: wagner@cbr.med.harvard.edu.

The publication costs of this article were defrayed in part by page charge payment. Therefore, and solely to indicate this fact, this article is hereby marked "advertisement" in accordance with 18 U.S.C. section 1734

(C) 2001 by The American Society of Hematology 
showed no effect of GP V deletion. ${ }^{15}$ Although these studies suggest that GP V is not required for the vWF binding activity of GP Ib, the role of GP V in GP Ib function remains unsolved because $\mathrm{GP} \mathrm{V}^{-1-}$ platelet adhesion in high shear stress conditions was not evaluated. We used 2 models to study $\mathrm{GP} \mathrm{V}^{-1-}$ platelet function. In one model, platelet adhesion and thrombus growth were monitored in real time in injured mesenteric arterioles of wild-type and GP $\mathrm{V}^{-1-}$ mice. GP $\mathrm{V}$ deficiency enhanced thrombus formation. Because thrombus formation in this model was thrombin dependent, these studies provide a direct in vivo demonstration that GP V deficiency results in an enhanced reactivity with thrombin. Surprisingly, the absence of GP V also enhanced platelet adhesion in this model. In a second model, platelet adhesion and thrombus growth were monitored in vitro using heparinized blood of each genotype. GP V deletion had no effect on platelet adhesion to vWF at high shear rates where thrombin activity was inhibited by heparin. Thus, the enhanced in vivo adhesion of $\mathrm{GP}^{-1-}$ platelets was also attributed to an increased reactivity of these platelets to thrombin. We also observed an unexpected role for GP V in thrombus stabilization.

\section{Materials and methods}

\section{Mice}

The C57BL/6J/129Sv GP V V ${ }^{-1-}$ mice have been described. ${ }^{15}$ To minimize the influence of strain-dependent genetic differences, we produced the GP $\mathrm{V}^{+/+}$and $\mathrm{GP} \mathrm{V}^{-1-}$ mice in this study from the same GP $\mathrm{V}^{+/-}$colony. For the in vivo study, wild-type and $\mathrm{GP} \mathrm{V}^{-1-}$ mice were labeled as group $\mathrm{A}$ and $\mathrm{B}$, shipped to Boston, and intravital microscopy and tape analysis were

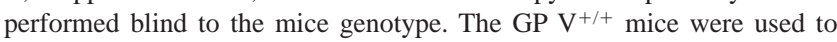
evaluate the effect of $\mathrm{r}$-hirudin. Experimental procedures were approved by the Animal Care and Use Committee of the Center for Blood Research.

\section{Flow cytometry}

Blood samples from 3 mice of each genotype were pooled and platelets isolated on a Sepharose 2B column. ${ }^{10}$ The platelets were fixed with $4 \%$ paraformaldehyde, washed, and incubated with 1:200 diluted fluorescein isothiocyanate (FITC)-hamster antirat $\beta_{1}$-integrin chain $\mathrm{Ha} 2 / 5$ (Pharmingen, San Diego, CA). Ten thousand platelets were analyzed using a BD FACScalibur (Becton Dickinson, San Jose, CA).

\section{In vivo thrombosis model}

The model was previously described. ${ }^{10,19}$ Male mice (3.5-4.5 weeks old) were injected with fluorescently labeled platelets $\left(5 \times 10^{6} / \mathrm{g}\right)$ of matching genotype in the lateral tail vein. The mice were anesthetized, and the mesentery was exteriorized through a midline abdominal incision. Arterioles were visualized with a Zeiss Axiovert 135 -inverted microscope $(32 \times, 0.4$ NA; Zeiss, Oberkochen, Germany) and recorded on videotape. $\mathrm{FeCl}_{3}(30 \mu \mathrm{L}$ of a $250-\mathrm{mM}$ solution) was applied to a certain section ( $\sim 2-5$ $\mathrm{mm}$ in length) of arteriole by topical application, which induced vessel injury and denudation of the endothelium..$^{10}$ Vessels were monitored for 40 minutes after injury or until full occlusion occurred (blood flow stopped) and lasted for more than 10 seconds. In all experiments, one arteriole was chosen in each mouse.

Several parameters were applied to describe the characteristics of thrombus formation: (1) early single-platelet deposition on the vessel wall, determined as the number of fluorescently labeled platelets that deposited on vessel wall per minute after injury; (2) the time required for the initiation of a thrombus of diameter more than $20 \mu \mathrm{m}$; (3) thrombus stability by determining the number of thrombi of diameter more than $30 \mu \mathrm{m}$ embolized away from the viewing field before the vessel occluded; (4) occlusion time of vessel, that is, time required for blood to stop flowing; and (5) site of vessel occlusion, that is, at the site of injury or downstream.
For hirudin inhibition, fluorescently labeled wild-type platelets were mixed with r-hirudin $(5 \mathrm{mg} / \mathrm{kg}$ ) (kindly provided by Dr Jawed Fareed, Loyola University, Chicago, IL) immediately before injection into the tail vein.

\section{In vitro thrombosis model}

Blood was collected by inserting a heparin-coated glass capillary tube (Drummond Scientific, Broomall, PA), cut to a length of $2 \mathrm{~cm}$, into the retro-orbital vein of mice at least 8 weeks old. The animals were anesthetized to prevent pain and discomfort, and euthanized at the end of the procedure according to institutionally approved procedures and with veterinarian supervision. The blood freely flowing through the capillary tube was collected into a plastic vial containing a freshly prepared 1000 USP U/mL solution of heparin sodium (Sigma, St Louis, MO) in HEPES-buffered saline, $\mathrm{pH} 7.4$, in a quantity sufficient to give a final concentration of $20 \mathrm{U} / \mathrm{mL}$ in the expected volume of blood.

Glass coverslips were coated with acid-insoluble fibrillar type I collagen from bovine Achilles tendon (Sigma) as previously described.,2,20 After rinsing, a coverslip was used as the lower surface of a modified Hele-Shaw flow chamber, ${ }^{21,22}$ in which a silicone rubber gasket determined a flow path height of $125 \mu \mathrm{m}$. A syringe pump (Harvard Apparatus, Holliston, MA) was used to aspirate blood at selected shear rates measured at the inlet of the flow chamber, where all measurements of platelet adhesion and thrombus formation were made, as previously reported. ${ }^{2}$ Platelets were labeled in whole blood by direct incubation with the fluorescent dye mepacrine (quinacrine dihydrochloride; $10 \mu \mathrm{M}$, final concentration). Although this dye also labels leukocytes, the latter could be readily distinguished from platelets by their relatively large size and the presence of nuclei. Red cells were not visualized due to fluorescence quenching by hemoglobin. Previous studies have shown that mepacrine does not interfere with platelet adhesion and thrombus formation.,23 Platelet thrombus formation was directly visualized in the flow chamber, in real time, using an epifluorescence inverted microscope (Axiovert 135M) coupled to a confocal system (LSM 410; both from Carl Zeiss). All events were recorded with a video cassette recorder (Sony, model 9500) at the acquisition rate of $30 \mathrm{frames} / \mathrm{s}$. Confocal sections at 1.0- $\mu \mathrm{m}$ intervals in the $z$-axis were obtained during blood flow with a 488-nm laser and scanning times of 1 or $2 \mathrm{~s} / \mathrm{section}$, depending on thrombus height. The microscope settings, including contrast, brightness, magnification, and pinhole aperture, were maintained constant to facilitate comparisons between different experiments.

All image analysis functions were performed with the Metamorph software package (Universal Imaging Corp, release 4.0, Downingtown, PA). Two-dimensional evaluation of initial platelet adhesion was performed on single-frame images captured from the recorded experiments at the sampling rate of 1 frame/s using a computer-controlled video cassette recorder and a frame grabber (Matrox Image LC, Dorval, Quebec, Canada). The digitized images, composed of $512 \times 512$ pixels each with a side of 0.5 $\mu \mathrm{m}$, were processed to adjust brightness and contrast to optimal levels, and a threshold was applied to distinguish platelets from background. Time was calculated by referring to the frame number. The total volume of thrombi in a defined area of the collagen-coated surface was estimated from series of confocal sections obtained at predetermined times from the onset of blood flow. The same threshold value was used in all analyses of confocal images for a given experiment. The area occupied by all thrombi in a given plane was calculated and the volume corresponding to a $1.0-\mu \mathrm{m}$-thick section was estimated by multiplying the average area covered by platelets in 2 consecutive planes by the height of the section $(1.0 \mu \mathrm{m})$. The total volume occupied by all thrombi was then estimated by linear interpolation with the summation of the sectional volumes.

\section{Statistical analysis}

Data are presented as mean \pm SEM. Statistical significance was assessed by $t$ test or by $\chi^{2}$ test and the Mann-Whitney test as indicated. 
A
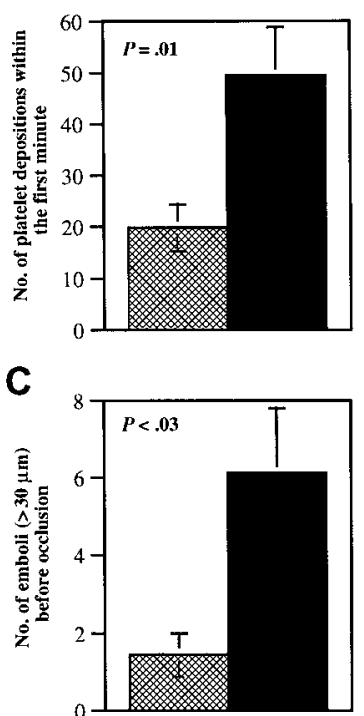

B

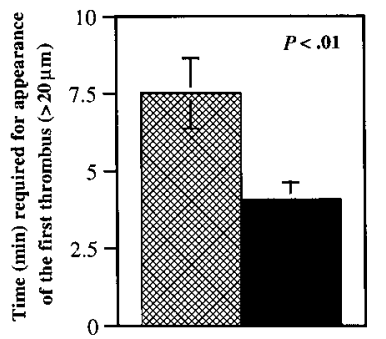

D

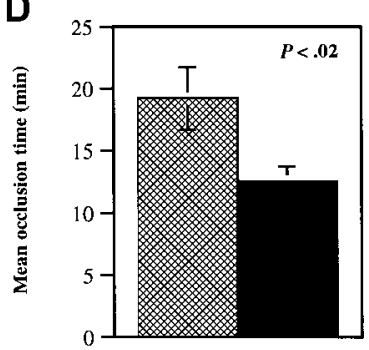

Figure 1. Quantitative analysis of thrombi formation in wild-type and GP $\mathbf{V}^{-1-}$

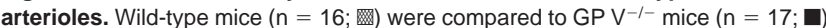
The diameter of the mesenteric arterioles was $103 \pm 3 \mu \mathrm{m}$ in wild-type mice and $104 \pm 3 \mu \mathrm{m}$ in $\mathrm{GP} \mathrm{V}^{-1-}$ mice, $P=.95$. The shear rates were $1529 \pm 46 / \mathrm{s}$ in wild-type and $1441 \pm 58 / \mathrm{s}$ in knockout mice, $P=.24$. Experiments were performed without knowledge of the mice genotypes. (A) The number of fluorescently labeled platelets that came in contact with the vessel walls in the first minute after $\mathrm{FeCl}_{3}$ injury was counted over a 410- $\mu \mathrm{m}$ length of vessel. (B) The time required for the appearance of the first thrombus (diameter $>20 \mu \mathrm{m}$ ) after injury was measured. Thrombi appeared about 4 minutes sooner in GP $\mathrm{V}^{-1-}$ mice than in wild-type mice. (C) The number of large emboli (diameter $>30 \mu \mathrm{m}$ ), generated in the period before vessel occlusion and embolized away from the viewing field, was determined. Although this period was shorter in GP V $\mathrm{V}^{-1-}$ mice (panel D), the number of emboli formed in these mice was higher. (D) The time before blood flow completely stopped for more than 10 seconds was determined. If blood flow did not cease during the 40-minute observation period, 40 minutes was used as the occlusion time. The vessel occlusion time in GP $\mathrm{V}^{-1}$ mice was shorter than in wild-type mice, but only a small number of GP $\mathrm{V}^{-/-}$vessels were occluded by the original thrombus (35\%). The majority of vessels were occluded by large emboli, which caused occlusion either within the injured region $(24 \%)$ or downstream of injured region (41\%). All occlusions in wild-type vessels were caused by one of the original thrombi within the injured area.

\section{Results}

Premature platelet-vessel wall interaction in $\mathrm{GP} \mathrm{V}^{-/-}$mice

Glycoprotein $\mathrm{V}^{-1-}$ platelet adhesion to $\mathrm{vWF}$ at both low and moderate shear appears unimpaired in vitro, ${ }^{15,17}$ but bleeding time in the GP $\mathrm{V}^{-1-}$ mice is shortened. ${ }^{15} \mathrm{GP}$ Ib-V-IX complex is important for adhesion mainly at high shear, and therefore, small mesenteric arterioles denuded by ferric chloride were chosen for this study. Because $41 \%$ of the vessels in $\mathrm{GP} \mathrm{V}^{-1-}$

mice already formed significant thrombi (diameter $>20 \mu \mathrm{m}$ ) in the first 3 minutes, the adhesion of single platelets to the injured vessel wall was determined during the first minute after $\mathrm{FeCl}_{3}$ application. The number of fluorescent platelets interacting with the injured site was 2.5 -fold higher in $\mathrm{GP} \mathrm{V}^{-1-}$ mice than in wild-type mice (Figure 1A).

Several factors may control platelet-injured vessel wall interaction. These include the expression and activity of GP Ib-V-IX and of integrins, $\alpha_{2} \beta_{1}$ and $\alpha_{\mathrm{IIb}} \beta_{3}{ }^{1,2}$ Platelets from GP V ${ }^{-1-}$ mice have similar levels of GP Ib complex and $\alpha_{\mathrm{IIb}} \beta_{3} \cdot{ }^{15,17}$ Using flow cytometry, we determined that the expression of $\beta_{1}$-integrin on GP $\mathrm{V}^{-1-}$ platelets was also indistinguishable from wild type (not shown). Thus, functional state alterations rather than expression level changes are likely to account for the increase in plateletvessel wall interaction observed in $\mathrm{GP} \mathrm{V}^{-I-}$ mice following the injury. These could result either in facilitated GP Ib-vWF interactions or increased integrin adhesions, perhaps due to $\mathrm{GP} \mathrm{V}^{-1-}$ platelet hyperresponsiveness to thrombin.

\section{Accelerated thrombus formation and vessel occlusion in $\mathrm{GP} \mathrm{V}^{-/-}$mice}

Unlike platelet adhesion to the vessel wall, platelet aggregation is almost exclusively mediated by the $\beta_{3}$-integrins because no thrombus formation has been found in arterioles of $\beta_{3}{ }^{-1-}$ mice (Wagner and Hynes, manuscript in preparation). It has been reported by Ramakrishnan and colleagues that platelets lacking GP V are hyperresponsive to thrombin at low concentration. This was indicated by both platelet aggregation and soluble fibrinogen binding. ${ }^{15} \mathrm{Kahn}$ and colleagues did not detect this difference in thrombin sensitivity. ${ }^{17}$ In this study, we found that platelet aggregation at the site of vascular injury in $\mathrm{GP}^{-1-}$ mice was accelerated in comparison to wild type. Both the time required for the appearance of the first thrombus and the vessel occlusion time in GP $\mathrm{V}^{-I-}$ mice were significantly shorter than in wild-type mice (Figures $1 B, D$ and 2). This indicates that, in vivo, the activation of $\beta_{3}$-integrins occurs faster in the absence of GPV.

\section{Frequent embolization in GP $\mathrm{V}^{-/-}$mice}

In studies similar to the present, we observed that thrombi formed in fibrinogen-deficient mice appear unstable and frequently embolize from the injured site causing a downstream occlusion. ${ }^{10}$ Formation of large emboli can also be found in wild-type mice infused with tissue plasminogen activator ( $\mathrm{Ni}$ and Wagner, unpublished observation, 1999). These observations suggest that fibrin generated by thrombin action might be required for thrombi stabilization.

We were surprised to see that emboli formed in $\mathrm{GP} \mathrm{V}^{-1-}$ mice much more frequently than in wild type (Figures $1 \mathrm{C}$ and 2). These
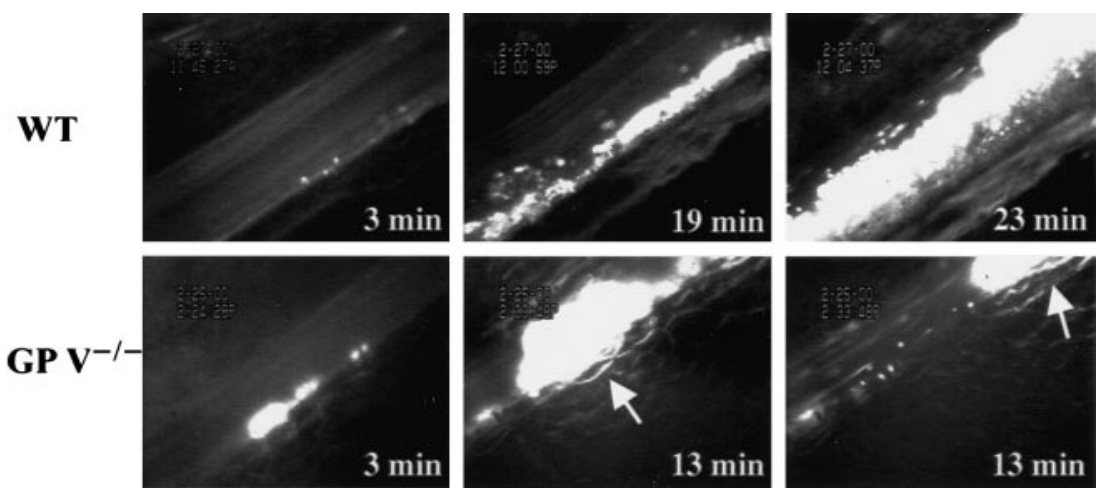

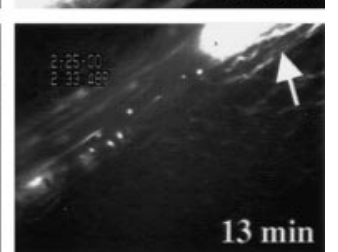

Figure 2. Characteristics of thrombus growth differ between wild-type and $\mathrm{GP} \mathbf{V}^{-1-}$ mice. Times after $\mathrm{FeCl}_{3}-$ induced injury are indicated $(\mathrm{min})$. In the wild-type arteriole, adherent fluorescently labeled platelets can be seen 3 minutes after $\mathrm{FeCl}_{3}$ treatment. A stable thrombus, present at 19 minutes, caused vessel occlusion at 23 minutes after injury. In GP V ${ }^{-I-}$ mice, the occurrences of platelet-vessel wall interactions and platelet aggregation were accelerated. Good size thrombi were seen as early as 3 minutes after injury. However, these thrombi were not stable. They were often stripped off the vessel wall by blood flow when they grew to occlusive size (2 sequential panels at 13 minutes) and led to a significant number of downstream occlusions. The arrows point to a moving thrombus. 
From www.bloodjournal.org by on January 13, 2009. For personal use only.

Table 1. Effect of thrombin inhibition on platelet deposition and thrombus formation at arteriolar shear

\begin{tabular}{|c|c|c|c|c|}
\hline Group & $\begin{array}{l}\text { Platelet deposition } \\
\text { (in the } 1 \mathrm{st} \text { min after injury) } \\
\text { Number of platelets/min }\end{array}$ & $\begin{array}{c}\text { Platelet deposition } \\
\text { (3-5 min after injury) } \\
\text { Number of platelets/min }\end{array}$ & $\begin{array}{l}\text { Time required for formation of } \\
\text { the first thrombus }(>20 \mu \mathrm{m}) \\
\text { (min) }\end{array}$ & $\begin{array}{l}\text { Mean vessel } \\
\text { occlusion time* } \\
\text { (min) }\end{array}$ \\
\hline Wild type $(n=16)$ & $19.8 \pm 4.6$ & $54.2 \pm 7.1$ & $7.5 \pm 1.1$ & $19.2 \pm 2.5$ \\
\hline Wild type + hirudin $(n=11)$ & $27.8 \pm 5.7$ & $33.5 \pm 5.4$ & $19.5 \pm 2.1$ & $39.6 \pm 0.4$ \\
\hline$P$ & $P=.3$ & $P<.05$ & $P<.0001$ & $P<.0001$ \\
\hline
\end{tabular}

Mesenteric arterioles from hirudin-treated mice were explored and monitored as described in "Materials and methods." Although no inhibition has been observed in the first minute, significantly less platelet adhesion to the vessel was found between 3 and 5 minutes after injury. The thrombus initiation and vessel occlusion were also dramatically inhibited by hirudin.

*If vessel did not occlude, the end time of observation (40 min) was used.

†Some of the wild-type results are also shown in Figure 1.

emboli were larger than those in fibrinogen-deficient mice. We called them "occlusive size emboli" because they usually embolized only when they nearly filled the lumen of the vessels. Thirteen of 17 vessels in $\mathrm{GP} \mathrm{V}^{-1-}$ mice (77\%) formed occlusive size emboli, whereas only 1 of 16 vessels $(6 \%)$ in wild-type mice formed such a large embolus $\left(\chi^{2}=16.65, P<.005\right)$. The observed embolization led to the occurrence of downstream occlusions in $\mathrm{GP} \mathrm{V}^{-1-}$ mice $(41 \%)$ not seen in wild type $(0 \%)\left(\chi^{2}=8.34, P<.005\right)$.

\section{A}

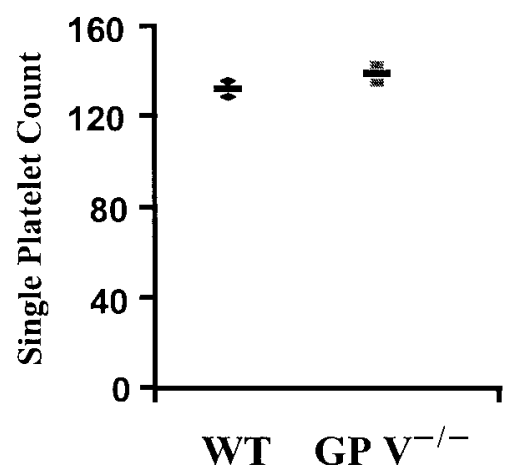

B

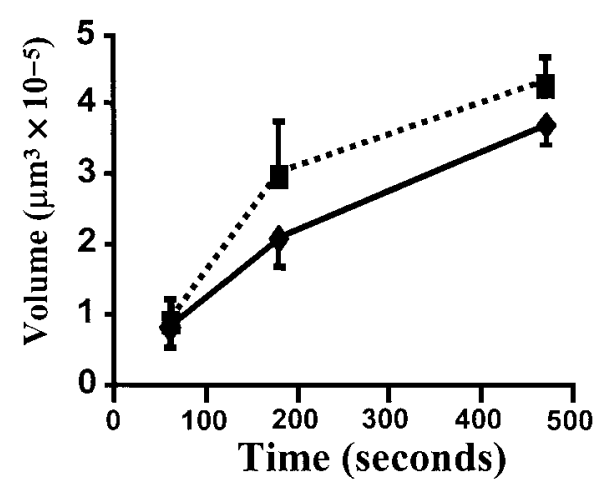

Figure 3. In vitro platelet adhesion and aggregation in the presence of heparin. (A) Single-platelet adhesion. Either GP V ${ }^{+/+}(\bullet)$ or $\mathrm{GP} \mathrm{V}^{-/-}(\mathbf{\square})$ mice were bled with heparin-coated glass capillary tubes and thrombin was further inhibited by heparin $(20 \mathrm{U} / \mathrm{mL})$. Fluorescently labeled blood samples were then perfused at a shear rate of $1500 \mathrm{~s}^{-1}$ in a flow chamber coated with collagen type I fibrils. Numbers of adherent platelets in the first 15 seconds were very similar in the 2 genotypes. $\mathrm{n}=2, P=.44$, Mann-Whitney test. The mean and individual values are shown. (B) Comparison of volumes of platelet thrombi formed in the in vitro thrombosis model. Heparin-treated blood samples were perfused at shear rate of $1500 \mathrm{~s}^{-1}$ and total volumes of thrombi were determined after 60,180 , and 470 seconds. No significant differences were found between GP $\mathrm{V}^{+/+}(-)$and $\mathrm{GP} \mathrm{V}^{-/-}$mice (---). $\mathrm{n}=3, P>.27$ at all time points tested, Mann-Whitney test. The mean \pm SEM is shown.

\section{Critical role of thrombin in platelet adhesion and thrombus growth in vivo}

To understand whether increased thrombogenesis in $\mathrm{GP} \mathrm{V}^{-1-}$ mice was due to $\mathrm{GP} \mathrm{V}^{-1-}$ platelet hyperresponsiveness to thrombin, ${ }^{15}$ we examined how hirudin, a potent thrombin inhibitor, ${ }^{24,25}$ affects thrombogenesis in our in vivo thrombosis model of arteriolar injury. Experiments were performed using wild-type mice. Although no significant difference has been found in platelet-vessel wall interaction in the first minute, this interaction was inhibited about $40 \%$ between 3 to 5 minutes after injury. The times required for the first thrombus formation and vessel occlusion were dramatically prolonged (Table 1). Only 2 of 11 hirudin-treated arterioles, but 14 of 16 control arterioles, were occluded within 40 minutes. We did not observe frequent large emboli formation in hirudintreated mice, but thrombi dissolution did occur. Thus, thrombininduced platelet activation plays an important role in this arteriolar injury model and probably is the major reason for accelerated thrombus growth in $\mathrm{GP} \mathrm{V}^{-1-}$ mice.

\section{GP V V $^{-1}$ platelets adhere and aggregate normally in vitro at high shear when thrombin is inhibited}

To clarify whether the enhancement of platelet adhesion and aggregation in vivo was indeed caused by thrombin signaling or by a change in GP Ib affinity for vWF at high shear, single-platelet adhesion and thrombus volume were measured in perfusion chambers. These chambers were coated with fibrillar type I collagen and perfused with whole blood anticoagulated with heparin. The platelet adhesion in this system is fully dependent on GPIb-vWF interaction. ${ }^{26}$ Interestingly, there was no difference in the number of single platelets adhering after perfusion of wild-type or $\mathrm{GP} \mathrm{V}^{-/-}$blood at $1500 / \mathrm{s}$ for 15 seconds (Figure 3A). Similarly, the volume of thrombi formed in the following 8 minutes of perfusion was comparable between the 2 genotypes (Figure 3B). Thus, we have no evidence that the function of the GPIb complex in binding to vWF is enhanced in the absence of GP V. Rather, it appears that the differences observed in vivo (Figure 1) are due to thrombin-induced signaling, which is eliminated in vitro by the presence of heparin.

\section{Discussion}

Two important conclusions on the role of GP V in platelet function and thrombus formation have been made from the present study. First, the absence of GP V increases both platelet adhesion and aggregation in an in vivo mouse model ${ }^{10,19}$ that is dependent on both thrombin and vWF. No significant effect of GP V deletion was observed in adhesion and thrombus formation in a high-shear, 
From www.bloodjournal.org by on January 13, 2009. For personal use only.

vWF-dependent ex vivo model. Accordingly, the enhanced adhesion and thrombosis observed in vivo appears to be solely due to the negative modulation function of GP V in thrombin-induced platelet activation. Second, the absence of GP V decreases thrombus stabilization. These findings suggest a critical role for GP V hydrolysis in thrombosis.

Glycoprotein V is a prominent, constitutively expressed protein on the platelet surface, with approximately 11000 copies being part of the GP Ib-V-IX complexes. Previous studies established that GP V is a negative modulator of the activity of thrombin-induced platelet activation. ${ }^{15,16}$ The absence of GP V, such as occurs in GP $\mathrm{V}^{-1-}$ platelets or as occurs following thrombin-induced cleavage of GP V, allows GP Ib to become a functional thrombin receptor. We now observe that both platelet adhesion and thrombus formation are increased in GP $\mathrm{V}^{-1-}$ mice following vascular injury. We considered that GP V may function in this model to affect thrombin-induced platelet activation ${ }^{15,16,27,28}$ and influence GP Ib-vWF interaction. ${ }^{29}$ The effect of the direct thrombin inhibitor hirudin was tested to determine whether thrombin plays an important role in promoting platelet adhesion at arteriolar shear. Hirudin reduced firm single-platelet adhesion in wild-type mice as is seen 3 to 5 minutes after $\mathrm{FeCl}_{3}$ injury. This demonstrates that thrombin is necessary to induce optimal activation of platelet adhesion receptors such as the integrins. The effect of hirudin was less on the initial transient platelet-vessel wall interaction (Table 1) that is mediated by $\mathrm{vWF}^{10}$ because at this time little thrombin may be present in the platelet environment. However, this small amount of thrombin may be sufficient to enhance GP $\mathrm{V}^{-/-}$platelet adhesion (Figure 1A) because these platelets appear hyperresponsive to low concentrations of thrombin. ${ }^{15,16}$ When thrombin action was prevented by heparin, the hyperadhesivity of the GP $\mathrm{V}^{-/-}$ platelets to the substratum and to each other was eliminated (Figure 3 ). To determine whether the absence of GP V affected GP Ib-vWF

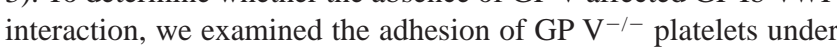
high shear. We found that the adhesion was not affected by the absence of GP V. This finding agrees with previous in vitro studies that also did not detect alterations of GP Ib-mediated adhesion to vWF in static assays in the absence of GP V. ${ }^{15,17,18}$ Because thrombin is involved in both adhesion and aggregation, because GP $\mathrm{V}^{-1-}$ platelets have enhanced responsiveness to thrombin, and because GP $\mathrm{V}^{-1-}$ platelets have normal binding to $\mathrm{vWF}$, we conclude that the increased platelet subendothelium interaction and aggregation under high shear in $\mathrm{GP} \mathrm{V}^{-1-}$ mice (Figure 1A,B) in the injury model (Table 1) were caused by increased responsiveness to thrombin. Taken together, these data suggest that thrombin is involved in the earliest steps of thrombus formation, including platelet adhesion to the injured vessel wall.

Previous work by Lanza and coworkers ${ }^{30}$ has established that the increased thrombin generation caused by infusion of thromboplastin into rats causes the accumulation of GP Vf1, a soluble, hydrolytic fragment of GP V, in plasma and a concomitant decrease of the GP V in platelets. Because $\mathrm{GP} \mathrm{V}^{-/-}$platelets have increased participation in thrombosis (this study), and because platelets pretreated with thrombin to cleave GP V have a similar enhanced reactivity to thrombin as do $\mathrm{GP} \mathrm{V}^{-1-}$ platelets, ${ }^{16}$ one can speculate that individuals with platelets with cleaved GP V, for example resulting from prior exposure to thrombin, would be at increased risk of thrombosis.

The mechanism involved in the increased thrombus embolization in $\mathrm{GP} \mathrm{V}^{-1-}$ mice is not clear. One explanation is that the rate of thrombus growth is faster in $\mathrm{GP} \mathrm{V}^{-1-}$ mice than in wild-type mice, and that this rapid growth may not allow for efficient fibrin polymerization that may be needed for the stabilization of the thrombus. In addition, $\alpha$-thrombin bound to GP Ib $\alpha$ cannot clot fibrinogen. ${ }^{31}$ Thus, one could postulate that absence of GP V, by allowing more $\alpha$-thrombin binding to GP $\mathrm{Ib}$, interferes with fibrinogen conversion to fibrin in the aggregates. A second explanation is that GP V may be required for the formation of the high-affinity thrombin-binding sites on the platelet surface, ${ }^{32}$ and that the high-affinity binding sites could form a thrombin reservoir. ${ }^{33}$ The release of thrombin from this "reservoir" and subsequent conversion of additional fibrinogen to fibrin may prevent thrombus embolization in the late stage, tipping the balance of coagulation toward hemostasis. This thrombin reservoir would be less active or absent in $\mathrm{GP} \mathrm{V}^{-/-}$animals. It would be interesting to illustrate a positive role of GP V in fibrin formation in the thrombi, but for the moment we have no direct evidence for such activity. A third explanation is based on previous studies showing that GP V is a negative modulator of thrombin activation of platelets. ${ }^{15}$ Because GP Ib has overlapping binding domains for both vWF and thrombin, ${ }^{6,34}$ the high local thrombin concentration generated within a thrombus ${ }^{35}$ may, in the absence of GP V, displace vWF bound to GP Ib.

The increased embolization of thrombi in the $\mathrm{GP} \mathrm{V}^{-1-}$ mice may be relevant to human disease. It is now recognized that a burst of thrombin generation can be induced following clot formation, resulting in up to a near quantitative conversion of prothrombin to thrombin. ${ }^{35}$ Because GP V cleavage occurs even at low levels of thrombin, the GP V on platelets trapped within a thrombus would be predicted to be substantially cleaved. Given that $\mathrm{GP}^{-1-}$ thrombi have increased embolization, this raises the possibility that GP V cleavage may be a mechanism driving thrombus embolization. These considerations suggest that monitoring of GP Vf1 in patient populations at risk for thrombosis or at risk for thrombus embolization may be of value in identifying patients at high risk.

\section{Acknowledgments}

We thank Faisal Mahmood Khan for help with intravital microscopy and Lesley Cowan for assistance preparing the manuscript.

\section{References}

1. Ruggeri ZM. Mechanisms initiating platelet thrombus formation. Thromb Haemost. 1997;78:611616.

2. Savage B, Almus-Jacobs F, Ruggeri ZM. Specific synergy of multiple substrate-receptor interactions in platelet thrombus formation under flow. Cell. 1998:94:657-666.

3. Lopez JA, Andrews RK, Afshar-Kharghan V, Berndt MC. Bernard-Soulier syndrome. Blood. 1998;91:4397-4418.

4. Berndt MC, Gregory C, Kabral A, Zola H, Fournier
D, Castaldi PA. Purification and preliminary characterization of the glycoprotein lb complex in the human platelet membrane. Eur J Biochem. 1985; 151:637-649.

5. Modderman PW, Admiraal LG, Sonnenberg A, von dem Borne AE. Glycoproteins V and Ib-IX form a noncovalent complex in the platelet membrane. J Biol Chem. 1992;267:364-369.

6. Katagiri Y, Hayashi Y, Yamamoto K, Tanoue K, Kosaki G, Yamazaki H. Localization of von Willebrand factor and thrombin-interactive domains on human platelet glycoprotein Ib. Thromb Haemost. 1990;63:122-126

7. Matsushita T, Sadler JE. Identification of amino acid residues essential for von Willebrand factor binding to platelet glycoprotein lb: charged-toalanine scanning mutagenesis of the $\mathrm{A} 1$ domain of human von Willebrand factor. J Biol Chem. 1995;270:13406-13414.

8. Goto S, Ikeda Y, Saldivar E, Ruggeri ZM. Distinct mechanisms of platelet aggregation as a consequence of different shearing flow conditions. J Clin Invest. 1998;101:479-486. 
9. Kulkarni S, Dopheide SM, Yap CL, et al. A revised model of platelet aggregation. J Clin Invest. 2000; 105:783-791.

10. Ni H, Denis CV, Subbarao S, et al. Persistence of platelet thrombus formation in arterioles of mice lacking both von Willebrand factor and fibrinogen. J Clin Invest. 2000;106:385-392.

11. Tsuji S, Sugimoto M, Miyata S, Kuwahara M, Kinoshita S, Yoshioka A. Real-time analysis of mural thrombus formation in various platelet aggregation disorders: distinct shear-dependent roles of platelet receptors and adhesive proteins under flow. Blood. 1999;94:968-975.

12. Okumura T, Hasitz M, Jamieson GA. Platelet glycocalicin: interaction with thrombin and role as thrombin receptor of the platelet surface. J Biol Chem. 1978;253:3435-3443.

13. De Marco L, Mazzucato M, Masotti A, Fenton JW, 2nd, Ruggeri ZM. Function of glycoprotein lb alpha in platelet activation induced by alpha-thrombin. J Biol Chem. 1991;266:23776-23783.

14. Berndt MC, Phillips DR. Interaction of thrombin with platelets: purification of the thrombin substrate. Ann N Y Acad Sci. 1981;370:87-95.

15. Ramakrishnan V, Reeves PS, DeGuzman F, et al Increased thrombin responsiveness in platelets from mice lacking glycoprotein V. Proc Natl Acad Sci U S A. 1999;96:13336-13341.

16. Ramakrishnan V, DeGuzman F, Bao M, Hall SW, Leung LL, Phillips DR. A thrombin receptor function for platelet glycoprotein Ib-IX unmasked by cleavage of glycoprotein V. Proc Natl Acad Sci U S A. 2001;98:1823-1828.

17. Kahn ML, Diacovo TG, Bainton DF, Lanza F, Trejo J, Coughlin SR. Glycoprotein V-deficient platelets have undiminished thrombin responsiveness and do not exhibit a Bernard-Soulier phenotype. Blood. 1999:94:4112-4121.
18. Cranmer SL, Ulsemer P, Cooke BM, et al. Glycoprotein (GP) Ib-IX-transfected cells roll on a von Willebrand factor matrix under flow: importance of the GPib/actin-binding protein (ABP-280) interaction in maintaining adhesion under high shear. J Biol Chem. 1999;274:6097-6106.

19. Denis $C$, Methia N, Frenette PS, et al. A mouse model of severe von Willebrand disease: defects in hemostasis and thrombosis. Proc Natl Acad Sci U S A. 1998;95:9524-9529.

20. Folie BJ, McIntire LV, Lasslo A. Effects of a novel antiplatelet agent in mural thrombogenesis on collagen-coated glass. Blood. 1988;72:13931400.

21. Usami S, Chen HH, Zhao Y, Chien S, Skalak R. Design and construction of a linear shear stress flow chamber. Ann Biomed Eng. 1993;21:77-83.

22. Savage B, Saldiver E, Ruggeri ZM. Initiation of platelet adhesion by arrest onto fibrinogen or translocation on von Willebrand factor. Cell. 1996: 84:289-297.

23. Ruggeri ZM, Dent JA, Saldivar E. Contribution of distinct adhesive interactions to platelet aggregation in flowing blood. Blood. 1999;94:172-178.

24. Rydel TJ, Ravichandran KG, Tulinsky A, et al. The structure of a complex of recombinant hirudin and human alpha-thrombin. Science. 1990;249: 277-280.

25. Turpie AG, Weitz JI, Hirsh J. Advances in antithrombotic therapy: novel agents. Thromb Haemost. 1995;74:565-571.

26. Ware J, Russell S, Ruggeri ZM. Generation and rescue of a murine model of platelet dysfunction: the Bernard-Soulier syndrome. Proc Natl Acad Sci U S A. 2000;97:2803-2808.

27. Calverley DC, Kavanagh TJ, Roth GJ. Human signaling protein 14-3-3zeta interacts with platelet glycoprotein lb subunits Ibalpha and Ibbeta. Blood. 1998;91:1295-1303.
28. Andrews RK, Harris SJ, McNally T, Berndt MC. Binding of purified 14-3-3 zeta signaling protein to discrete amino acid sequences within the cytoplasmic domain of the platelet membrane glycoprotein Ib-IX-V complex. Biochemistry. 1998;37: 638-647.

29. Fredrickson BJ, Dong JF, Mclntire LV, Lopez JA Shear-dependent rolling on von Willebrand factor of mammalian cells expressing the platelet glycoprotein Ib-IX-V complex. Blood. 1998;92:36843693.

30. Ravanat C, Freund M, Mangin P, et al. GPV is a marker of in vivo platelet activation-study in a rat thrombosis model. Thromb Haemost. 2000;83: 327-333.

31. De Marco L, Mazzucato M, Masotti A, Ruggeri ZM. Localization and characterization of an alpha-thrombin-binding site on platelet glycoprotein Ib alpha. J Biol Chem. 1994;269:6478-6484.

32. Dong JF, Sae-Tung G, Lopez JA. Role of glycoprotein $\mathrm{V}$ in the formation of the platelet high-affinity thrombin-binding site. Blood. 1997;89:43554363.

33. Leong L, Henriksen RA, Kermode JC, Rittenhouse SE, Tracy PB. The thrombin high-affinity binding site on platelets is a negative regulator of thrombin-induced platelet activation: structurefunction studies using two mutant thrombins, Quick I and Quick II. Biochemistry. 1992;31:25672576.

34. De Luca M, Facey DA, Favaloro EJ, et al. Structure and function of the von Willebrand factor $\mathrm{A} 1$ domain: analysis with monoclonal antibodies reveals distinct binding sites involved in recognition of the platelet membrane glycoprotein Ib-IX-V complex and ristocetin-dependent activation. Blood. 2000;95:164-172.

35. Mann KG. Biochemistry and physiology of blood coagulation. Thromb Haemost. 1999;82:165-174. 